\title{
A microfluidic device with fluorimetric detection for intracellular components analysis
}

\author{
Radosław Kwapiszewski • Maciej Skolimowski • \\ Karina Ziółkowska • Elżbieta Jędrych • Michał Chudy • \\ Artur Dybko • Zbigniew Brzózka
}

Published online: 11 January 2011

(C) The Author(s) 2011. This article is published with open access at Springerlink.com

\begin{abstract}
An integrated microfluidic system that coupled lysis of two cell lines: L929 fibroblasts and A549 epithelial cells, with fluorescence-based enzyme assay was developed to determine $\beta$-glucocerebrosidase activity. The microdevice fabricated in poly(dimethylsiloxane) consists of three main parts: a chemical cell lysis zone based on the sheath flow geometry, a micromeander and an optical fibers detection zone. Unlike many methods described in literature that are designed to analyse intracellular components, the presented system enables to perform enzyme assays just after cell lysis process. It reduces the effect of proteases released in lysis process on determined enzymes. Glucocerebrosidase activity, the diagnostic marker for Gaucher's disease, is the most commonly measured in leukocytes and fibroblasts using 4-methylumbelliferyl- $\beta$-D-glucopyranoside as synthetic $\beta$-glucoside. The enzyme cleavage releases the fluorescent product, i.e. 4-methylumbelliferone, and its fluorescence is measured as a function of time. The method of enzyme activity determination described in this paper was adapted for flow measurements in the microdevice. The curve of the enzymatic reaction advancement was prepared for three reaction times obtained from application of different flow rates of solutions introduced to the microsystem. Afterwards, determined $\beta$-glucocerebrosidase activity was recalculated with regard to $10^{5}$ cells present in samples used for the tests.
\end{abstract}

R. Kwapiszewski $(\bowtie) \cdot$ K. Ziółkowska $\cdot$ E. Jędrych $\cdot$ M. Chudy ·

A. Dybko $\cdot$ Z. Brzózka

Department of Microbioanalytics, Institute of Biotechnology,

Warsaw University of Technology,

Warsaw, Poland

e-mail: rkwapiszewski@ch.pw.edu.pl

\section{Skolimowski}

Department of Micro- and Nanotechnology,

Technical University of Denmark,

Copenhagen, Denmark
The obtained results were compared with a cuvette-based measurements. The lysosomal $\beta$-glucosidase activities determined in the microsystem were in good correlation with the values determined during macro-scale measurements.

Keywords Cell lysis · Sheath flow - Optical detection . $\beta$-glucocerebrosidase activity Gaucher's disease

\section{Introduction}

Microbioanalytics is an interdisciplinary domain in the midst of chemistry, medicine, molecular biology and engineering. Recently, this discipline has become very stimulating for many research groups and it is still developing. Due to miniaturization and microbioanalytical achievements many experiments are feasible at the cellular level and they provide important information for better understanding of processes investigated. Almost every significant life process is dependent on enzyme activity (Ville et al. 1998). Enzymes are biological catalysts responsible for supporting nearly all of the chemical reactions in cells that maintain animal homeostasis. Enzyme assays have become key elements in clinical diagnostics because of their role in maintaining life processes (Berg et al. 2001). Extraction of enzymes from cells is fundamental for many bioanalytical procedures, for example when a substrate used for an enzymatic reaction does not penetrate cell membranes. Thus, cell lysis process is necessary to be performed. It is needed in most cell biology techniques to extract not only intracellular components such as proteins but also DNA and RNA (Elizabeth et al. 2002).

Animal cell lysis leads to disintegration of the plasma membrane which is the barrier separating cell contents from the environment. There are many different methods of cell 
lysis: thermal, electrical, mechanical, acoustic, and chemical (Brown and Audet 2008). These methods were successfully applied in microfluidic systems. However, the choice of lysis protocol depends on the assay and careful selection of the proper lysis technique are essential for gathering accurate data from analyzed sample containing cell suspension. Thermal cell lysis is commonly used as a preparatory step in nucleic acids analysis based on PCR (polymerase chain reaction). He et al.(2001) described an integrated monolithic microchip device which used thermal cycling to accomplish E. coli lysis and PCR amplification of DNA. However, the thermal lysis is not ideal for protein extraction because of their denaturation at high temperature. Electrical cell lysis is based on electroporation process which causes formation of small pores in the cell membrane and makes it permeable to external medium. An example of the microdevice for the electrical lysis was demonstrated by Wang et al. (2006). Due to its speed and reagentless procedure the interest in electrical lysis of cells on a microfluidic platform has increased recently. Mechanical methods of cell lysis are also relatively effective and reagentless. Most of them take advantage of shear stress phenomenon to disrupt cells. Kim et al. (2004) used spherical particles in microfluidic CD platform (Compact Disc) and performed the lysis process with the efficiency of approximately $65 \%$. However, it is difficult to apply mechanical lysis for a single cell analysis.

Chemical methods, which disrupt cell membranes using detergents, solvents and antibiotics, are also widely used for lysis (Sethu et al. 2004; Carlo et al. 2005). Lytic agents effectively incorporate into cell membrane and form mixed micelles with isolated phospholipids and membrane proteins (le Maire et al. 2000). Ocvirk et al. (2004) designed a Y-shape microchannel to perform the cell lysis within $30 \mathrm{~s}$ using mild, non-ionic Triton X-100, and within 2 s using ionic sodium dodecyl sulfate (SDS). The cell lysis using SDS is simple, fast and high-throughput. However, it has some limitations because SDS denaturates proteins and interferes with subsequent biological assays. Selection of proper cell lysis buffer highly depends on assays performed. In case of intracellular components' examinations the non-denaturing cell lysis buffer containing Triton X-100 as a main constituent is the most widely used. The cell lysis process is usually the first step in medical diagnostics procedures, which enables the determination of wide range of therapeutic biomarkers, e.g. substrate concentration, gene expression and enzyme activity.

Currently more than 3000 congenital metabolic diseases are known, for example: mitochondrial (Thorburn 2004), peroxisomal (Shimozawa 2007), lysosomal (Ashok 2005) etc. Most of them are caused by the abnormal value of enzyme activity. Gaucher's disease (GD) is the most common of the lysosomal storage disorders (LSDs) caused by the deficiency of $\beta$-glucocerebrosidase (lysosomal $\beta$ glucosidase, $\beta$-Glc) (EC 3.2.1.42), the enzyme that participates in the degradation of glycosphingolipids (Grabowski and Horowitz 1997). This enzyme is characterized by the accumulation of glucocerebroside in liver, spleen and bones. The prevalence of GD in the population has been estimated at about 1:50000 (Grabowski 2008). GD is relatively common among Ashkenazi Jews, occurring in about 1:500 people (Beutler et al. 1993). There are three clinical subtypes of GD that are inherited as autosomal recessive traits. Type I Gaucher's disease (non-neuronopathic) is the most popular form. Patients can experience hepatosplenomegaly, anemia, thrombocytopenia, and bone abnormalities. Expression of these symptoms is extremely variable. Some individuals are devastated by the disease processes in the first decade of life. Type II (acute neuronopathic) is characterized by such neurologic symptoms as muscles hypertonicity and persistent retroflexion. Patients have extensive and progressive brain damage usually before they reach the age of two. Finally, patients with the third type of Gaucher's disease (Type IIIsubacute neuronopathic) show broad spectrum of clinical symptoms, generally including organomegaly and some neurologic dysfunction. Highly effective enzyme replacement therapy is available for most patients with types I and III of GD. This therapy causes decrease of liver and spleen size, reduction of skeletal anomalies, and successfully reverses other symptoms of the disorder. In principle, plasma, leukocytes and skin fibroblasts are mainly utilized for the enzymatic diagnosis. Beutler and Grabowski (2001) found out that individuals with GD show $10 \%$ of the normal activity of $\beta$-Glc.

Unfortunately, there is still a problem with diagnostics of heterozygote patients. They have half-normal enzyme activity, but there is an overlap with non-affected controls. Molecular analysis seems to be the best diagnosis method. However, there is a large number of mutations of gene coding $\beta$-Glc. Thus, it renders the biochemical study on the enzyme activity more accessible (de Fost et al. 2003). Nowadays, there are many approaches for screening of various LSDs. Different methods including spectrophotometric, fluorometric, radiometric, mass spectrometric or immunological assays have been used to determine intracellular proteins (Gelb et al. 2006). There is still no ideal biochemical screening method for newborns suffering from LSDs, especially for heterozygotes patients. There are large number of false-positive and false-negative results (Meikle et al. 2004). Each of currently applied methods has advantages and drawbacks and the choice of the method very often depends on clinical laboratory capabilities and personnel. Mass spectrometric and immunological assays are multiplexable. They may provide information on many proteins present in one sample, what very often reduces the 
time of analysis and makes the diagnostics procedure less complicated. The mass spectrometry seems to be powerful in clinical diagnostics of LSDs (Gelb et al. 2006; la Marca et al. 2009). It is extremely sensitive and repeatable technique. However, MS instruments are expensive and are still not widely used in clinical laboratories. Moreover, the short time of analysis with MS concerns only the detection step. The rest of steps such as: cell suspension preparation, performing of enzymatic reactions, or sample incubation, take even several hours. Spectrophotometric or fluorimetric methods are commonly used in many clinical laboratories and hospitals. Although they are not excellent for screening tests, they are appropriate to examine one protein at the time, and in fact to diagnose many of patients with the abnormal value of intracellular enzymes' activities.

Development of novel, effective diagnostic strategies and procedures, based on intracellular components analysis, is strongly related with applying micro total analysis systems $(\mu \mathrm{TAS})$. Apart from low reagents consumption, short reaction time, integration, automation, versatility, possibility of diagnostic monitoring and stimulation of each step of the procedure, the use of miniaturized microdevices in progressive clinical medicine (point of care systems, POCS) affects the patients' comfort (Figeys and Pinto 2000; Kutter 2000).

In this study we describe an integrated microsystem with optical detection for intracellular components analysis. Nowadays there are many approaches to determine the level of cellular compounds (Hadd et al. 1997; Clark et al. 2009), especially to perform enzyme assays (Wang 2002). Most of them are sensitive and have low detection limits. Unfortunately, many microfluidic chips described in the literature are combined with expensive and complicated instruments, e.g. de Boer et al. (2005) described a microsystem for bioactivity screening combined with capillary liquid chromatography and mass spectrometry. In many cases, before the actual analysis in a microsystem, the incubation of biological material with a substrate is required. This process may take even a few hours, which significantly extends the time of analysis. The goal of this work is to develop an easy to handle, cheap and versatile microsystem with a sensitive detection method. Apart from these advantages, the microsystem enables to perform enzymes activity determination just after cell lysis process. It significantly improves the quality of the results because there is a limited effect of proteases released during the lysis process on the analyzed enzymes. Brief description of investigations on the microsystem for intracellular enzyme activity analysis was reported previously (Chudy et al. 2009). In this paper, all details concerning the microdevice's fabrication and measurements of $\beta$-Glc in L929 fibroblasts are presented. Moreover, the next cell culture, A549 epithelial cells were investigated. After the validation of developed $\beta$-Glc activity determination method using fibroblasts from patients suffering from GD and control group, the presented microfluidic device will be ready for preliminary tests in clinical laboratories.

\section{Experimental}

\subsection{Microdevice fabrication}

Nowadays, there are several technologies for microsystems' fabrication using polymers. We decided to use the photolithography and the replica molding technique for PDMS structures preparation (McDonald et al. 2000). Details of the technology applied are given by Juchniewicz et al. (2009) therefore only a brief description is given in this paper. The first step of the microdevice structure fabrication was the preparation of a replica using capillary films. The capillary film is a UV sensitive emulsion precisely deposited on a flexible polyester foil. The thickness of the emulsion depends on the type of capillary film, and varies between 15 and $700 \mu \mathrm{m}$ (www.chromaline.com). In our case, the Pro/Cap 50 (Chromaline) Capillary Film with $50 \mu \mathrm{m}$ thick emulsion layer was used. It means that using this type of a capillary film we are able to fabricate $50 \mu \mathrm{m}$ high patterns for microchannels' replication in PDMS. A piece of the capillary film was attached to a solid support (PMMA, glass, etc.) and exposed with UV light through a photomask. UV exposure of the photosensitive layers can be performed with the use of various types of photomasks. The most precise patterns are obtained using glass/ chromium photomasks. However, in our case hi-res laser printed foil with the negative of the microchannels' network was sufficient for $50 \mu \mathrm{m}$ structures replication in PDMS. The exposed photosensitive layer was developed using water stream and it was dried using compressed nitrogen. In this way, a mold with a designed geometry for the structures' replication in PDMS was obtained. Degassed mixture of PDMS prepolymer with curing reagent with 10:1 weight ratio was poured into the mold and it was subsequently cured for $1 \mathrm{~h}$ at $60^{\circ} \mathrm{C}$. The whole fabrication procedure took only $2 \mathrm{~h}$ and the PDMS plate with precisely formed microchannels' network was obtained. The PDMS slab with the microchannels was immersed into liquid nitrogen and then the inlet and outlet holes for tubings were drilled. The next step of the fabrication procedure was microchannels' sealing using a plain PDMS slab. After cleaning with distilled water, both slabs were placed in a laboratory dryer at $70^{\circ} \mathrm{C}$ for $10 \mathrm{~min}$ and then exposed to oxygen plasma for $35 \mathrm{~s}$ (Plasma Preen System Inc. II 973). The plates were manually 
aligned, immediately put together and left for $2 \mathrm{~h}$ for bonding.

The microdevice was fabricated using PDMS (Dow Corning Sylgrad 184) as a material, because of its chemical inertness, non-cytotoxicity and biocompatibility (Mata et al. 2005). The transparency of PDMS enables microscope observation of the cell lysis process. Moreover, its hydrophobicity minimizes the risk of microchannels clogging by biological material used in analytical procedures.

\subsection{Microdevice geometry}

A schematic view of the integrated microdevice is presented in Fig. 1. The design of chemical cell lysis module is based on the sheath flow geometry (Hoffman et al. 2001). The goal of applying the sheath flow in the microdevice is to obtain a maximum efficiency of cell lysis process. There are three microchannels (each $120 \mu \mathrm{m}$ wide and $50 \mu \mathrm{m}$ deep), i.e. two side-focusing streams used for lysis buffer and the middle one for cell suspension and substrate mixture introduction. These three microchannels merge into a single channel and form a meander-shape microreactor (a length of $1 \mathrm{~m}$, a width of $300 \mu \mathrm{m}$ and a depth of $50 \mu \mathrm{m}$ ), in which the lysis process and the analytical enzymatic reaction undergo simultaneously.

The enzyme/substrate reaction runs in the microreactor. A length of $1 \mathrm{~m}$ of the microreactor is sufficient for effective fluid mixing and enough for detection of different fluorescent product's concentrations obtained by precise adjusting of solutions' flow rates (see Section 11).

\subsection{Optical fibers}

Measurements of fluorescent 4-methylumbelliferone (4-MU) released from lysed cells were carried out by quartz

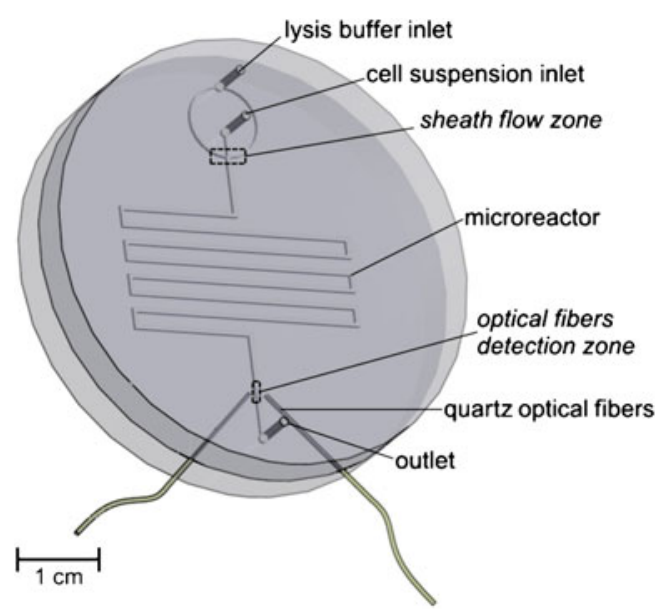

Fig. 1 Schematic view of integrated microsystem optical fibers (a diameter of $0.6 \mathrm{~mm}$ ) connected with a spectrofluorimeter (FluoroMax-3, Jobin Yvon Inc.). Although it was obligatory to use a quartz optical fiber for transmission the excitation light $\left(\lambda_{\mathrm{ex}}=320 \mathrm{~nm}\right)$, using a quartz optical fiber for detection was unnecessary. A detection quartz optical fiber could be replaced with a silica optical fiber, but then fluorescence background is significantly higher. Quartz optical fibers were perpendicularly inserted into guiding microchannels. The distance between microchannel and each optical fiber in the detection zone was $600 \mu \mathrm{m}$.

\subsection{Reagents and solutions}

Cells were lysed by the use of non-denaturing cell lysis buffer (pH 5.4) containing $10 \mathrm{mM}$ imidazole (Fluka), $0.5 \mathrm{M}$ sodium chloride (Fluka), 1\% Triton X-100 (Sigma Aldrich), $0.2 \mathrm{mM}$ sodium ortho-vanadate (Sigma Aldrich) and $0.2 \mathrm{mM}$ phenylmethylsulfonyl fluoride (PMSF, Fluka) dissolved in $100 \mathrm{ml}$ of DI water. The enzymatic reaction was initiated by the addition of the synthetic substrate 4-methylumbelliferyl- $\beta$-D-glucopyranoside (MUG, Fluka) dissolved in $0.2 \mathrm{M}$ sodium acetate buffer ( $\mathrm{pH}$ 5.4) to the final concentration of $3 \mathrm{mM} .0 .6 \%$ sodium taurocholate solution (ST) (Sigma Aldrich) was added to the reaction mixture to inhibit cytosolic and activate lysosomal $\beta$ glucosidase (Peters et al. 1976).

\subsection{Cells}

L929 mouse fibroblasts and A549 human lung adenocarcinoma cells (American Type Culture Collection) were used as the model cells for the analytical method optimization and evaluation. The culture medium for routine culture contained: $88.9 \%_{\mathrm{vol}}$ Minimum Essential Medium Eagle (MEME, Sigma Aldrich), 10\% $\%_{\mathrm{vol}}$ Fetal Bovine Serum (FBS, Gibco), 1\% $\%_{\text {vol }} 25 \mathrm{mM}$ L-glutamine (Sigma Aldrich) and $0.1 \%_{\mathrm{vol}} 100 \mathrm{mM}$ penicillin and streptomycin (Sigma Aldrich).

The cells were cultured in a $\mathrm{CO}_{2}$ cell culture incubator (HERAcell 150, Thermo Scientific) at $37^{\circ} \mathrm{C}$ and in the $5 \%$ $\mathrm{CO}_{2} \mathrm{~atm}$. The cells were passaged every 2 days. In order to prepare cell suspension the medium was removed from the culture flask and the cells were rinsed with PBS buffer (Phosphate Buffered Saline, Sigma Aldrich). Next, the cells were trypsinized using $0.25 \%$ trypsin in EDTA (Sigma Aldrich). The detached cells were suspended in pure MEME medium. The target cell density was about $10^{6}$ cells $/ \mathrm{mL}$.

Propidium iodide (PI, Sigma Aldrich) was used as a dye staining necrotic cells. The solution of $1 \mathrm{mg}$ of PI in $1 \mathrm{~mL}$ of PBS was added to culture medium to achieve concentration of $40 \mu \mathrm{g} / \mathrm{mL}$. 


\subsection{Measurement methods}

The enzyme activity measurement method developed by Peters et al. (1976) was modified and applied in micro- and macro-scale set-ups. In Peters' method a mixture of lysed leucocytes, MUG and sodium taurocholate dissolved with acetate buffer were incubated at $37^{\circ} \mathrm{C}$ for $30 \mathrm{~min}$. After incubation the enzymatic reaction was stopped by adding glycine- $\mathrm{NaOH}$ buffer ( $\mathrm{pH}$ 10.5), causing $\beta$-Glc inactivation. The amount of 4-MU released in the reaction was determined spectrofluorimetrically in alkaline $\mathrm{pH}$ (deprotonated form of 4-MU was measured). In the modified method (proposed in this paper) the enzyme/substrate reaction was not stopped by the glycine- $\mathrm{NaOH}$ buffer addition. In consequence the fluorescence intensity of protonated form of 4-MU was measured using the spectrofluorimeter at wavelength $\lambda_{\mathrm{em}}=445 \mathrm{~nm}$ after 4-MU excitation at wavelength $\lambda_{\mathrm{ex}}=320 \mathrm{~nm}$. Macro-scale experiments were performed for verification and evaluation of the proposed microdevice design and the flow-through microscale method of $\beta$-Glc activity determination.

\subsubsection{Macro-scale measurement}

The reaction mixture (total volume at $3.55 \mathrm{~mL}$ ) placed in a quartz cuvette contained: $0.5 \mathrm{~mL}$ cell suspension $\left(10^{5-} 10^{6}\right.$ cells), $50 \mu \mathrm{L}$ of cell lysis buffer, $21 \mathrm{mg}$ sodium taurocholate, and MUG dissolved in $3 \mathrm{~mL}$ of $0.2 \mathrm{M}$ acetate buffer (pH 5.4). Total concentration of MUG in the prepared reaction mixture was $3 \mathrm{mM}$. The fluorescence spectrum of MUG and 4-MU is presented in Figs. 2 and 3, respectively. The $\beta$-Glc activity was calculated using the slope value of the measured advancement reaction curve (i.e. $\mathrm{C}_{4-\mathrm{MU}}=\mathrm{f}($ time $\left.)\right)$ at $22^{\circ} \mathrm{C}$. In order to obtain the enzyme activity in $\mu \mathrm{U} / 10^{5}$ cells, where $1 \mathrm{U}$ means amount of $\mu$ moles of substrate converted per $1 \mathrm{~min}\left[\mathrm{U}=\mu \mathrm{mol} \mathrm{min}{ }^{-1}\right]$, following calculations were performed:

$\mathrm{A}_{\beta-\mathrm{Glc}}=\mathrm{X} \cdot \mathrm{a} \cdot \varphi$

where:

$\mathrm{A}_{\beta-\text { Glc }} \quad$ enzyme activity in $\mu \mathrm{U} / 10^{5}$ cells

$\mathrm{X}=6 \cdot 10^{10}$ factor to convert $\mathrm{mol} \cdot \mathrm{dm}^{-3} \cdot \mathrm{s}^{-1}$ to $\mu \mathrm{U} \cdot \mathrm{mL}^{-1}$

a slope value in $\mathrm{mol} \cdot \mathrm{dm}^{-3} \cdot \mathrm{s}^{-1}$ of $\mathrm{C}_{4-\mathrm{MU}}=\mathrm{f}($ time $)$ curve

$\varphi \quad$ cell density factor, giving the value of enzyme activity counted per $10^{5}$ cells

$\varphi=10^{5} / \mathrm{D}_{\mathrm{c}}$

where:

$\mathrm{D}_{\mathrm{c}} \quad$ cell density (number of cells in $1 \mathrm{~mL}$ of the reaction mixture)

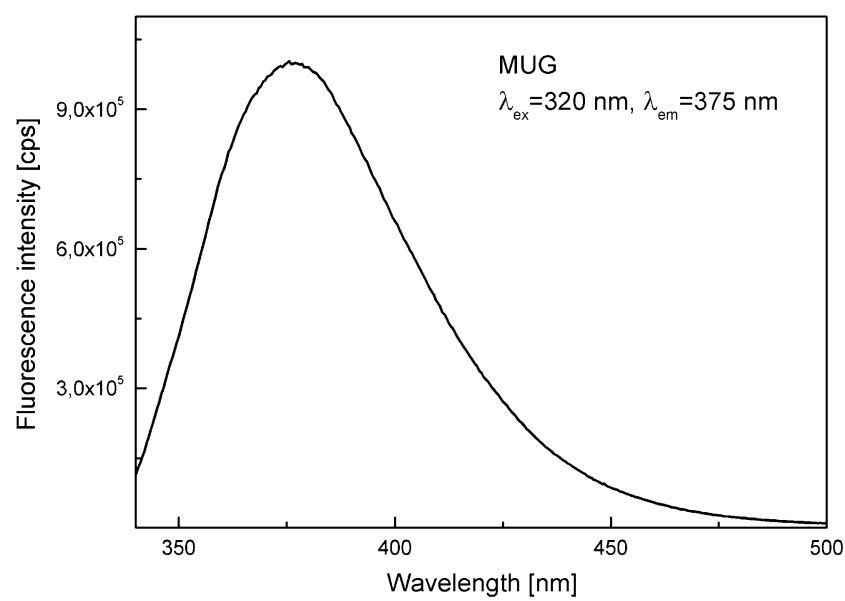

Fig. 2 The fluorescence spectrum of MUG

\subsubsection{Micro-scale measurement}

Micro-scale measurements of $\beta$-Glc activity were carried out in the presented microdevice (Fig. 4) with perpendicularly mounted optical fibers used for optical detection. The volume of the analysed reagents mixture in the optical fibers detection zone (see Fig. 1) is $7.5 \mathrm{~nL}$. Two syringe pumps were used to introduce the solutions in 1:4 flow rate ratio into the microsystem. Solution dosed by the first syringe pump contained cell suspension $\left(10^{5}-10^{6}\right.$ cells $\left./ \mathrm{mL}\right)$ (see Fig. 4a), $105 \mathrm{mg}$ sodium taurocholate and $15 \mathrm{mM}$ MUG dissolved in $0.2 \mathrm{M}$ sodium acetate buffer ( $\mathrm{pH}$ 5.4). The second syringe pump (with 4-fold higher flow rate than the first one) was used for dosing non-denaturing cell lysis buffer ( $\mathrm{pH}$ 5.4). The amount of 4-MU released in the enzyme/substrate reaction is strictly dependent on the duration of this reaction. In order to determine the advancement reaction curve and calculate the $\beta$-Glc activity, the enzymatic reaction was carried out for different reaction times: $60 \mathrm{~s}, 90 \mathrm{~s}, 120 \mathrm{~s}$. These reaction times were

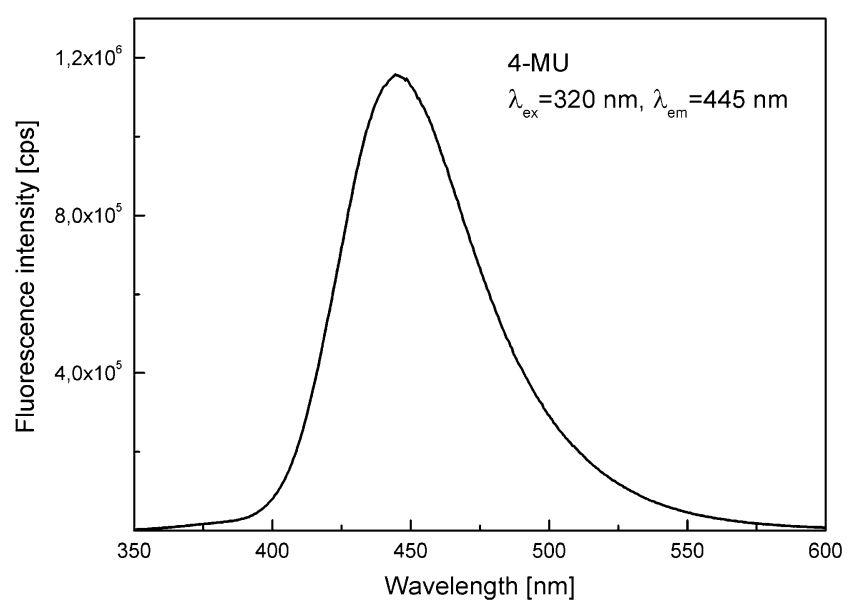

Fig. 3 The fluorescence spectrum of 4-MU 
Fig. 4 A photograph of integrated microsystem. Picture A shows the cell suspension introduced to microchannel. Picture B shows the one cell focused in the sheath flow zone and picture $\mathrm{C}$ shows necrotic cells dyed with propidium iodide

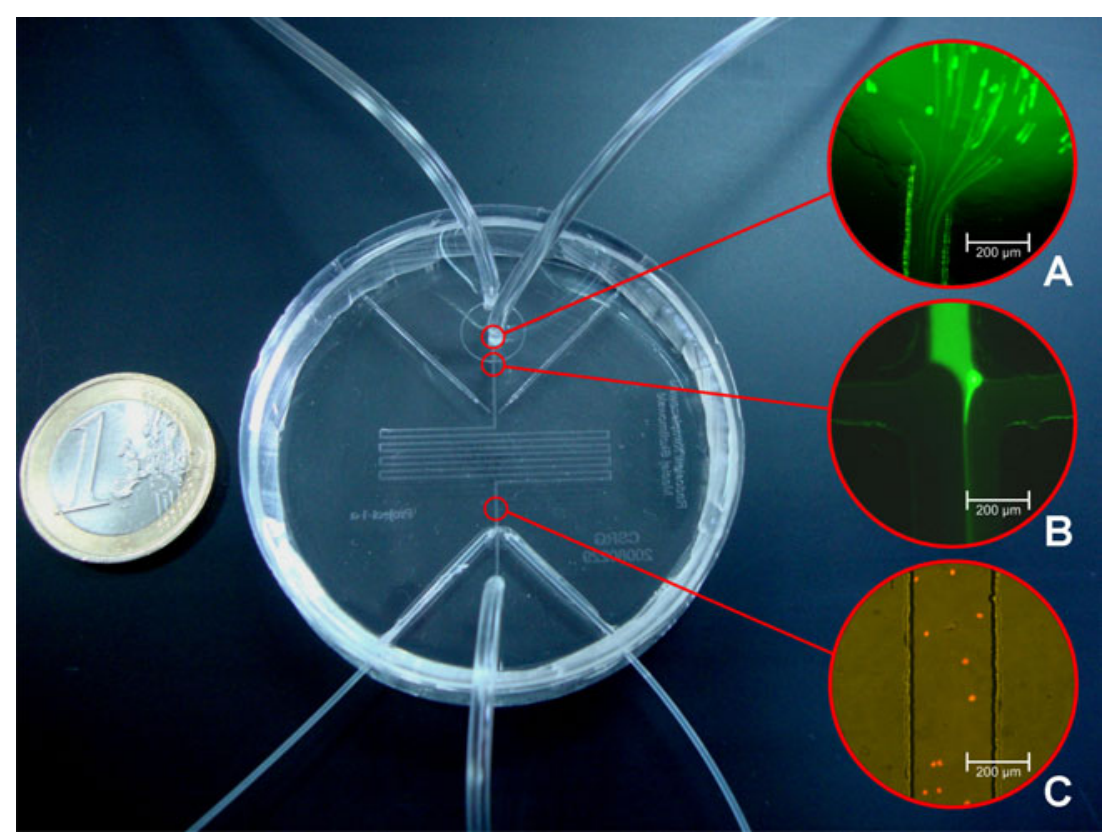

obtained by applying different flow rates with constant ratio of solutions introduced into the microsystem. The activity of $\beta$-Glc in micro-scale was calculated similarly to macroscale using the (1) equation.

\section{Results and discussion}

\subsection{Sheath flow parameters optimization}

In order to obtain highly efficient chemical lysis process in the microsystem, instead of a Y-shaped microchannel, a hydrodynamic focusing was applied. A sheath flow geometry enables immediate contact of each introduced to the microchannel cell with the lysis buffer. The diameter of L929 fibroblast and A549 epithelial cells used in experiments is approximately $12-13 \mu \mathrm{m}$ and it is also the desired width of the middle stream with the cell suspension. The flow rates ratio of fluids introduced into the microdevice determines the width of the streams. Thus, they were investigated and optimized (see Fig. 5). Comsol Multiphisics 3.3 software was used for flow rates simulations of focusing process (see columns C and D). In simulations the Navier-Stokes equation for incompressible fluids and the Fick's second law for mass transport between phases were used. It can be seen in Fig. 5/column D, that due to the diffusion the stream is tapered. To obtain comparable data, the width of the stream was measured in the zone of cell's first contact with the cell lysis buffer (normalized $c=0.8$ ). Obtained results were verified by the measurements of fluorescence intensity profiles in streams' junction zone (Fig. 5/column E). The required middle stream's width of $15 \mu \mathrm{m}$ was obtained by applying flow rates of the lysis buffer and cell suspension/substrate mixture in the ratio of $4: 1$.

\subsection{Preliminary macro-scale experiments}

The first step of our investigations was to perform the cell lysis process, which is essential in different cell analysis. This process was studied by the microscopic observation of cells' morphology after their treatment with non-denaturing cell lysis buffer (see Fig. 6). The changing shape of cells and membrane disruption were possible to perceive. In order to confirm the microscopic observations the fluorescent test with the PI as a dye was performed. PI intercalates nucleic acids of necrotic cells and gives red fluorescent light, when the sample was excitated with a $\lambda_{\mathrm{ex}}=535 \mathrm{~nm}$. Different volumes of the lysis buffer in the range of 5-200 $\mu \mathrm{L}$ were added to the cell culture flasks containing $5 \mathrm{~mL}$ of cell suspension (approximately $10^{6}$ cells $/ \mathrm{mL}$ ). The volume of $80 \mu \mathrm{L}$ of the cell lysis buffer was determined as a minimal to perform rapid and effective cell membrane disintegration.

The next step was to study the influence of the mixture ingredients on the fluorescence intensity during measurements of enzyme activity (Fig. 7). Elimination of some ingredients from the mixture consisted of L929 fibroblasts (or A549 epithelial cells), substrate MUG, sodium acetate buffer, cell lysis buffer and the detergentsodium taurocholate, allowed to estimate their effect on the detected signal. For the mixture without MUG (Fig. 7/curve A) the fluorescence intensity was not changing. Obtained low and stable signal indicates that, except of MUG, the other ingredients are not fluorescent. In case of cells' exclusion from the reaction mixture (Fig. 7/curve B) the increase of 
Fig. 5 Sheath flow parameters optimization-simulation and experiments results comparison

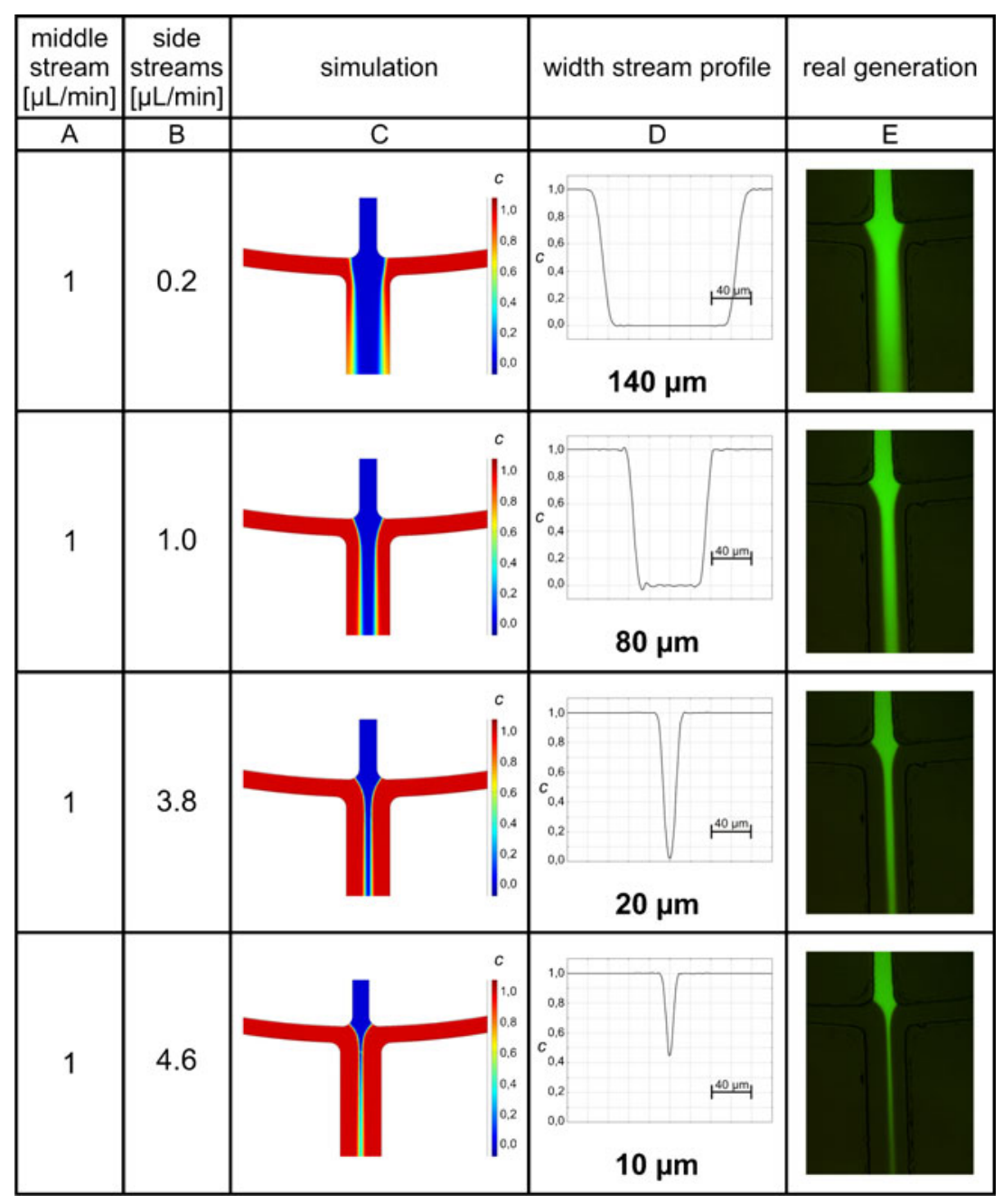

fluorescence also was not observed. Constant signal observed indicates that MUG does not hydrolyze spontaneously in solutions applied: lysis and sodium acetate buffers. Only slight increase in the fluorescence intensity was observed for the mixture that did not contain the cell lysis buffer (Fig. 7/ curve C). It is a proof that some cells present in the cell suspension used in the experiments were disrupted. It was also proved using PI as a dye for necrotic cells, that about $8 \%$ of total amount of the cells after passage is disintegrated. Moreover, UV light applied for 4-MU excitation during the measurements may also harmfully affect the cells. To prove our hypothesis additional experiment was carried out. PI was added to the cell suspension and the increase in necrotic cells number was observed for half an hour. It was calculated that about $5 \%$ cells died after this time. It explains the increase in the fluorescence intensity in time. The difference in slope values of the measured curves of the mixture without the cell lysis buffer and the reaction mixture contained all ingredients (Fig. 7/curve D) indicates that MUG does not penetrate the cell membrane and the cell lysis is the necessary process to perform in order to determine $\beta$-Glc activity.
3.3 Measurement of $\beta$-glc activity in a macro-scale

In order to calculate $\beta$-glucocerebrosidase activity, the slope value of the measured advancement reaction curve (i.e. $\mathrm{C}_{4-\mathrm{MU}}=\mathrm{f}(\mathrm{time})$ ) was determined (see Experimental Section). Enzyme activity assays were performed 5 times, each assay for fresh prepared stock cell suspension (Table 1). The limit of detection (LOD), determined by the concentration that gave a signal 3 times the standard deviation of the blank, was $5 \mu \mathrm{M}$ for 4-MU. The calculated $\beta$-Glc activity in $\mathrm{L} 929$ fibroblasts at $22^{\circ} \mathrm{C}$ was $110.2 \mu \mathrm{U} / 10^{5}$ cells and the standard deviation was less than $20 \%$, whereas in A549 epithelial cells was $34.6 \mu \mathrm{U} / 10^{5}$ cells with the standard deviation of this value also less than $20 \%$. The obtained results were used as reference values to compare with the results obtained in a micro-scale.

\subsection{Measurement of $\beta$-glc activity in a micro-scale}

In comparison with the methods conventionally used to determine the $\beta$-Glc activity, the one of the most important 
Fig. 6 A microscopic observation of the lysis process of L929 fibroblasts using a nondenaturing cell lysis buffer $(100 \mu \mathrm{L}$ of a cell lysis buffer was added to $1 \mathrm{~mL}$ of cell suspension), and FDB and PI as fluorescent dyes. Picture (A) - cell suspension without a lysis buffer; picture (B)-after $10 \mathrm{~s}$; picture (C) - after $20 \mathrm{~s}$; picture (D) - after $30 \mathrm{~s}$
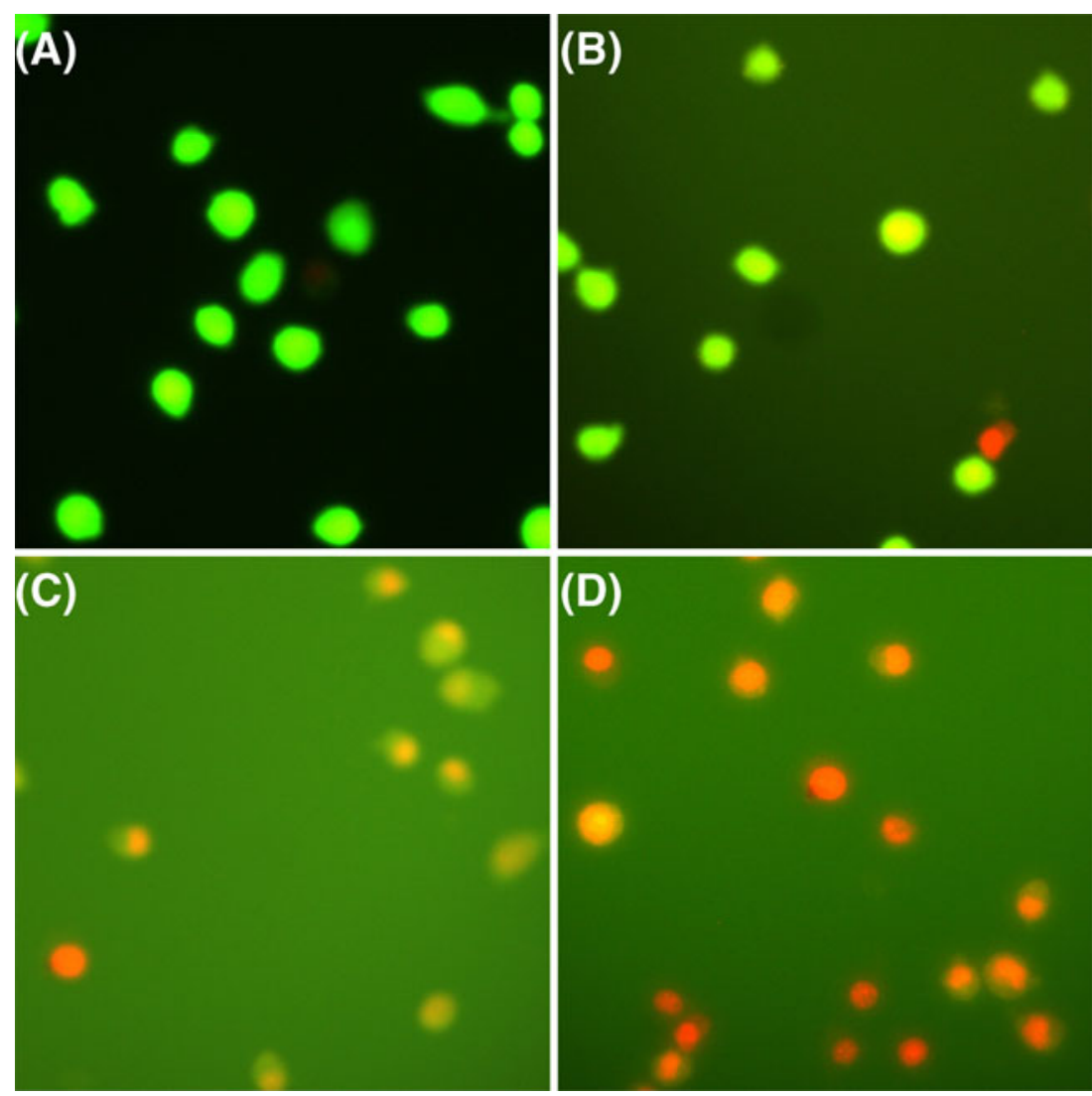

advantages of the presented microdevice is performing of enzymatic reaction just after cell lysis process. Released enzyme molecules to the reagent mixture react with an excessive amount of MUG (the enzymatic reaction must be independent of the substrate concentration). Although reagents mixture contains protease inhibitors, the possibility of inhibiting some $\beta$-Glc molecules by proteases after cell

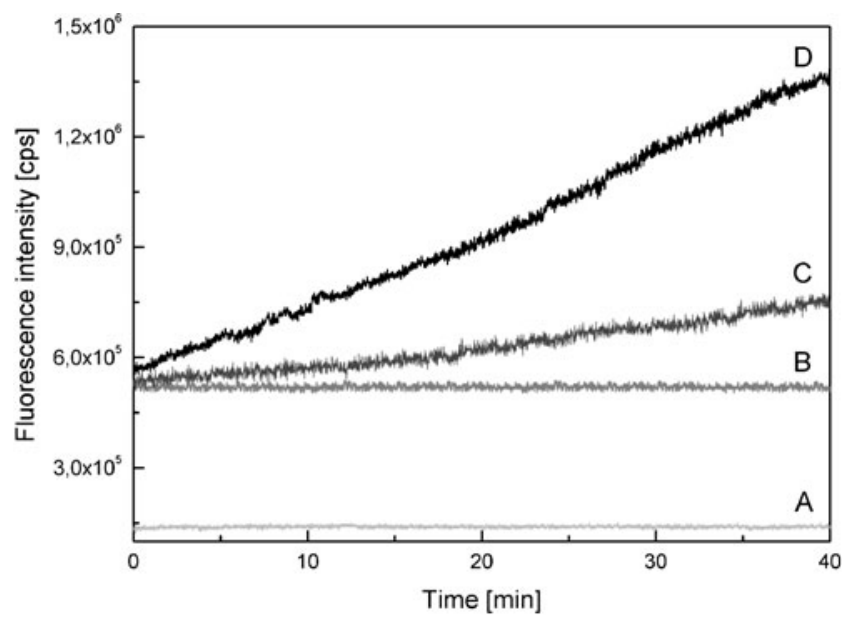

Fig. 7 Preliminary macro-scale experiments. Curves show: a fluorescence response of the mixtures: without MUG (a), without fibroblasts (b), without the cell lysis buffer (c), and a reaction mixture containing all ingredients $(\mathbf{d})$ lysis process is minimized. It is extremely important to avoid inactivation of the determined enzyme, especially, when it is hard to classify an individual to one of patients or carriers group.

The elaborated method of $\beta$-Glc activity measurement in the presented microsystem is based on determination of the fluorescence intensity of 4-MU for different enzymatic reaction times. The time of the enzymatic reaction for changed flow rates was estimated using two independent methods. The first one was based on calculations with parameters such as: dimensions of the microchannel and total flow rate of introduced to the microchip reagents. The second one was based on measurement of time of series microbubbles purposely introduced into the microchannel. Results obtained in both methods were in accordance with one to another. Times of $60 \mathrm{~s}, 90 \mathrm{~s}, 120 \mathrm{~s}$ were obtained for total fluid flows of $20 \mu \mathrm{L} / \mathrm{min}, 15 \mu \mathrm{L} / \mathrm{min}$ and $10 \mu \mathrm{L} / \mathrm{min}$, respectively. Additionally, it was stated that the cell suspension/substrate flow rate cannot be less than $2 \mu \mathrm{L} / \mathrm{min}$, because below this value, the cells agglomerate in the inlet chamber causing microchannels' clogging. The curve of advancement of the enzymatic reaction (Fig. 8) was estimated for three different reaction times obtained by the change of substrates' flow rates were kept in the constant 4:1 ratio. Application of more than three different reaction times was not necessary. It was checked that measurements of $\beta$-Glc activity at higher 
Table 1 Results of $\beta$-Glc activity determination

\begin{tabular}{|c|c|c|c|}
\hline Cell line & Scale & $\begin{array}{l}\text { Enzyme activity } \\
{\left[\mu \mathrm{U} / 10^{5} \text { cells }\right]}\end{array}$ & $\begin{array}{l}\text { Average enzyme } \\
\text { activity }\left[\mu \mathrm{U} / 10^{5} \text { cells }\right]\end{array}$ \\
\hline \multirow[t]{8}{*}{ L929 } & \multirow[t]{4}{*}{ Macro } & $\begin{array}{r}86 \\
114\end{array}$ & \multirow[t]{4}{*}{$110.2 \pm 19.6$} \\
\hline & & 131 & \\
\hline & & 126 & \\
\hline & & 94 & \\
\hline & \multirow[t]{4}{*}{ Micro } & $\begin{array}{l}90 \\
90\end{array}$ & \multirow[t]{4}{*}{$95.0 \pm 15.0$} \\
\hline & & 75 & \\
\hline & & 112 & \\
\hline & & 108 & \\
\hline \multirow[t]{10}{*}{ A549 } & \multirow[t]{5}{*}{ Macro } & 45 & \multirow[t]{5}{*}{$34.6 \pm 6.3$} \\
\hline & & 32 & \\
\hline & & 36 & \\
\hline & & 29 & \\
\hline & & 31 & \\
\hline & \multirow[t]{5}{*}{ Micro } & 16 & \multirow[t]{5}{*}{$24.4 \pm 6.2$} \\
\hline & & 20 & \\
\hline & & 27 & \\
\hline & & 28 & \\
\hline & & 31 & \\
\hline
\end{tabular}

number of reaction times caused longer analytical procedure and did not improve precision of the method presented. Determination of the $\beta$-Glc activity in a micro-scale was performed for 5 samples from different stock cell suspensions (Table 1). The limit of detection (LOD) of the microscale fluorescence-based enzyme assay was $20 \mu \mathrm{M}$ for 4-MU. The calculated lysosomal $\beta$-glucosidase activity in L929 fibroblasts was $95.0 \mu \mathrm{U} / 10^{5}$ cells with the standard deviation about 15\%, whereas in A549 epithelial cells was $24.4 \mu \mathrm{U} / 10^{5}$ cells with the standard deviation about $25 \%$. Although the cell suspension density was estimated using cell counting chambers the enzyme activity determination method had to be supported by the microscope observations. Our further researches will be focused on development of a miniaturized cell cytometer that could resolve this problem and make this method independent of using a microscope. Moreover, the integration of the presented microdevice with temperature control system could make this method even more precise.

Comparison or verification of our results of $\beta$-Glc activity determination with the results obtained by other research groups that can be found in the literature is impossible. There is a lot of factors influencing the enzyme activity determination such as: source of enzyme, temperature, $\mathrm{pH}$ of used buffer solutions, addition of activators or inhibitors of intracellular isoenzymes, and even type of medium used for the cells' cultivation. Beutler et al. (1971) studied the $\beta$-glucosidase activity in fibroblasts from homozygotes and heterozygotes and they obtained 2.7-fold higher level of enzyme activity with MEM medium than with F-12 medium. It is a proof that the obtained results of the enzyme activity are highly related to used method and conditions in which assays were performed. One way to verify the method developed is to perform this method validation. Then, the $\beta$-Glc activity determination with different diagnostic methods using the same biological material from individuals and patients with GD should be performed.

\section{Conclusions}

The purpose of this work was to design and develop an integrated microdevice with optical detection for intracellular components analysis directly after cell lysis process. Following procedures described in the literature a novel approach was developed and its practical application in miniaturized systems was found. The usability of the microsystem presented was verified by performing assays of $\beta$-glucocerebrosidase activity in two different cell lines: L929 fibroblasts and A549 epithelial cells. The obtained results of $\beta$-Glc activity in a micro-scale were in good agreement with cuvette-based measurements. After the validation of the analytical procedure using fibroblasts from patients suffering from Gaucher's disease and control group the presented microsystem could be used for preliminary tests in clinical laboratory. Currently, there is no biochemical/enzymatic method that reliably identifies all carriers of Gaucher's disease. The degree of misclassification of obligate heterozygotes is unacceptably high, reaching even $35 \%$ of all of the currently available $\beta$-Glc assays. New approaches to calculate $\beta$-Glc activity and classification of people to right group of patients are still explored. The

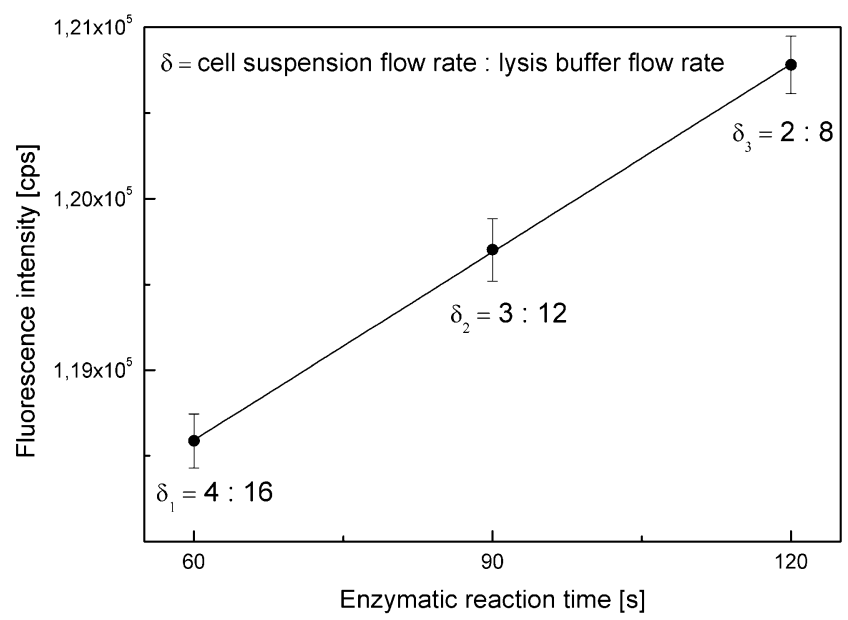

Fig. 8 The curve of the enzymatic reaction advancement measured in the microsystem 
presented microdevice should be appropriate for diagnostics of GD, as well as other LSDs, which diagnostic procedures are similar to those for GD. We hope that it will be an alternative for commonly applied and quite expensive disease diagnosis procedures utilized only in few clinical laboratories in Europe. Our further research will be focused on determining other intracellular compounds, integration of a cell counter system and a temperature control system in the microdevice.

Acknowledgements The authors would like to express their gratitude to dr Barbara Czartoryska from the Department of Genetics, Institute of Psychiatry and Neurology, Warsaw, Poland for her scientific advices concerning lysosomal storage disorders.

This work has been supported by the European Union in the framework of European Social Fund through the Warsaw University of Technology Development Programme, and was realized with a frame of project MNS-DIAG, which is financed by the European Union through the European Regional Development Fund and the Polish state budget in the framework of the Operational Programme Innovative Economy 2007-2013, contract No.UDA-POIG.01.03.01-00-014/08-01.

Open Access This article is distributed under the terms of the Creative Commons Attribution Noncommercial License which permits any noncommercial use, distribution, and reproduction in any medium, provided the original author(s) and source are credited.

\section{References}

V. Ashok, Br. J. Haematol. 128, 413 (2005)

J.M. Berg, J.L. Tymoczko, L. Stryer, Biochemistry (WH Freeman and Company, New York, 2001)

E. Beutler, W. Kuhl, F. Trinidad, R. Teplitz, H. Nadler, Am. J. Hum. Genet. 23, 62 (1971)

E. Beutler, N.J. Nguyen, M.W. Henneberger, Am. J. Hum. Genet. 52, 85 (1993)

E. Beutler, G.A. Grabowski, The metabolic and molecular basis of inherited disease. Gaucher disease (McGraw-Hill, New York, 2001), pp. 3635-3656

A.R. de Boer, B. Bruyneel, J.G. Krabbe, H. Lingeman, W.M.A. Niessen, H. Irth, Lab Chip 5, 1286 (2005)

R.B. Brown, J. Audet, J. R. Soc. Interface 5, S131 (2008)

D.D. Carlo, C. Ionescu-Zanetti, Y. Zhang, P. Hung, L.P. Lee, Lab Chip 5, 171 (2005)
M. Chudy, I. Grabowska, P. Ciosek, A. Filipowicz-Szymańska, D. Stadnik, I. Wyzkiewicz, E. Jedrych, M. Juchniewicz, M. Skolimowski, K. Ziolkowska, R. Kwapiszewski, Anal. Bioanal. Chem. 395, 647 (2009)

A.M. Clark, K.M. Sousa, C. Jennings, O.A. MacDouglas, R.T. Kennedy, Anal. Chem. 81, 2350 (2009)

Y.H. Elizabeth, L. Mather, J.L. Bell, Anal. Bioanal. Chem. 372, 49 (2002)

D. Figeys, D. Pinto, Anal. Chem. 71, 330A (2000)

M. de Fost, J.M.F.G. Aerts, C.E.M. Hollak, Neth. J. Med. 61, 3 (2003)

M.H. Gelb, F. Turecek, C.R. Scott, N.A. Chamoles, J. Inherit. Metab. Dis. 29, 397 (2006)

G.A. Grabowski, M. Horowitz, Baillieres Clin. Hematol. 10, 635 (1997)

G.A. Grabowski, Lancet 372, 1263 (2008)

A.G. Hadd, D.E. Raymond, J.W. Halliwell, S.C. Jacobson, J.M. Ramsey, Anal. Chem. 69, 3407 (1997)

Y. He, Y.H. Zhang, E.S. Yeung, J. Chromatogr. A 924, 271 (2001)

O. Hoffman, P. Niedermann, A. Manz, Lab Chip 1, 108 (2001)

M. Juchniewicz, M. Chudy, Z. Brzózka, A. Dybko, Microfluid. Nanofluid. 7, 733 (2009)

J. Kim, S.H. Jang, G.Y. Jia, J.V. Zoval, N.A.D. Silvab, M.J. Madou, Lab Chip 4, 516 (2004)

J.P. Kutter, Trends Anal. Chem. 19, 352 (2000)

M. le Maire, P. Champeil, J.V. Møller, Biochim. Biophys. Acta Biomembr. 1508, 86 (2000)

G. la Marca, B. Casetta, S. Malvagia, R. Guerrini, E. Zammarchi, Anal. Chem. 81, 6113 (2009)

A. Mata, A.J. Fleischman, S. Roy, Biomed. Microdev. 7, 281 (2005)

J. McDonald, D. Duffy, J. Anderson, D. Chiu, H. Wu, Electrophoresis 21, 27 (2000)

P.J. Meikle, E. Ranieri, H. Simonsen, T. Rozaklis, S.L. Ramsay, P.D. Whitfield, M. Fuller, E. Christensen, F. Skovby, J.J. Hopwood, Pediatrics 114, 909 (2004)

G. Ocvirk, H. Salimi-Moosavi, R.J. Szarka, E.A. Arriaga, P.E. Andersson, R. Smith, N.J. Dovichi, D.J. Harrison, Proc. IEEE 92, 115 (2004)

S.P. Peters, P. Coyle, R.H. Glew, Arch. Biochem. Biophys. 175, 569 (1976)

P. Sethu, M. Anahtar, L.L. Moldawer, R.G. Tompkins, M. Toner, Anal. Chem. 76, 6247 (2004)

N. Shimozawa, J. Inherit. Metab. Dis. 30, 193 (2007)

D.R. Thorburn, J. Inherit. Metab. Dis. 27, 349 (2004)

C.A. Ville, E.P. Solomon, C.E. Martin, D.W. Martin, L.R. Berg, P.W. Davis, Biology, 2nd edn. (Saunders, Philadelphia, 1998)

H. Wang, A.K. Bhunia, C. Lu, Biosens. Bioelectron 22, 582 (2006)

J. Wang, Electrophoresis 23, 713 (2002) 